\title{
Using Drama to Promote Sustainable Health among Rural Folk in Benue State: Ikyaan and Amua Workshops
}

\author{
*Desen Jonathan MBACHAGA
}

\begin{abstract}
In the last two decades, global efforts have focused on the high maternal mortality which is most common in third world countries. It is on the basis of this that the UN general assembly in 2016, adopted the UN Millennium Development Goals (now Sustainable Development Goals) as a basic framework for sustainable development, especially in third world countries. In many rural areas in Nigeria, women give birth without appropriate care from professional health caregivers and most of them have no adequate information and knowledge about antenatal clinic or understand the need for facility based delivery as against home based delivery. Using Ikyaan and Amua communities in Benue State as reference points, this article discusses the use of drama as a tool for community education towards enhancing maternal health consciousness among rural women in order to engender development (positive change). The findings reveal that prior to the drama intervention participants had low knowledge on the need for clinic based delivery because most women felt no harm in delivering with an untrained traditional birth attendant (TBA) or an older woman. But discussions and reflections after the $\mathrm{TfD} /$ performance made them to understand that complications could arise which would require professional care, including emergency situations that might require surgery. Also, the study observed during plenary regarding mother to child transmission (MTCT) that most people believe that if one is taking the Anti Retroviral drugs (ART) one would not need to use condoms since the drugs control the virus $\ddot{i}$ this misconception was corrected. The conclusion reached is that access to good health is one of the most
\end{abstract}

*Desen Jonathan MBACHAGA of the Department of Theatre and Media Arts, Federal University, Oye-Ekiti Email: desenmbachaga@yahoo.com 
serious challenges faced by women in third world countries. Hence, the article suggests, among other things, to improve maternal health, policymakers and planners should utilize alternative approaches which create avenues for public communication regarding health literacy so as to effectively empower people to take action to improve their health.

Keywords: Drama, Ikyaan, Amua, Safe motherhood, Sustainable health, MTCT, ART, TBA

\section{Introduction}

The right to health is a fundamental human right and safe motherhood is not only womenôs right but one that has been neglected with tragic consequences. The reality that in the $21^{\text {st }}$ century one in twenty African women will die of conditions related to pregnancy and childbirth is indicative of the limited chances and choices facing the majority of African women. It is also a reflection of the lack of access to an effective health system. Although poorer women are at greater risk, because of factors such as malnutrition leaving them with smaller pelvises and greater iron deficiency in pregnancy, it has been shown that effective care can dramatically reduce this risk.

At the core of significantly reducing morbidity and mortality is a birth assisted by skilled attendants, ante-natal care to address risks during pregnancy and capacity to refer women with complication to a hospital capable of providing basic emergency obstetric care, such as caesarean sections. Care by traditional and other lesser skilled birth attendants has been shown to be ineffective. However, skilled care coverage at delivery is only available to 42 percent of women in Africa. Furthermore, many who need referral will die because of lack of communication and transport to the hospital, or because the care required there is not available (Eric, 2003). It, therefore, means that, simply developing programmes that focus on disease eradication without building the means necessary for their delivery will lead us nowhere because if and when a woman chooses to become a mother, she has a right to 
quality and affordable health care and support throughout her pregnancy period and after she has put to bed.

Seventeen SDGs established in 2016 form the basis for a new development agenda globally. One of the seventeen goals to be achieved by 2030 is to provide good health and well being. This particular SDG specifically relates to womenôs health and their wellbeing. The National Health Policy for Nigeria states that, ñthe goal of the national health policy shall be levels of health that will enable all Nigerians achieve socially and economically productive livesò (Federal Ministry of Health, 2005). This policy aligns itself with two of eight MDGs earlier highlighted at the United Nations International Conference on Population and Development (ICPD) and the Millennium Summit in New York in which a set of eight socio-economic goals of development were adopted. It is imperative to note that ñdespite improvements in health among developing countries there has been little success in reducing a toll on womenô lives which results from child bearingò (Marie Stopes International, 2004).

Several studies on safe motherhood show that maternal mortality and morbidity affect women of all ages and nationalities. The need to take decisive steps towards reducing and preventing maternal deaths among women, especially those in rural areas is a priority concern for this study because creating an atmosphere whereby communities will take steps to address the issue of making pregnancy safer (MPS) by cultivating attitude change is imperative. According to (United Nations Population Fund (UNFPA) Nigeria (2006), maternal mortality ratio is very high and estimated at 740 per 100,000 live births, varying from 165 in the southwest to 1,549 in the north east. Also, the National Population Commissionôs National Demographic and Health Survey (NDHS) reports that only $36 \%$ of mothers received delivery care from professional health care providers é and puts infant mortality rates at 113 per 1,000 live births (2013). It submits further that ñNigeriâ̂ maternal mortality ratio is the tenth highest in the world, with 576 maternal deaths per 100000 live births and about 40000 maternal deaths recorded annually. The uptake of antenatal care (ANC) remains low in the country: in 2013 only $61 \%$ of pregnant women accessed ANC at least once from a skilled provider. Also, 
only $36 \%$ of pregnant women delivered at a health-care facilityò (2013).

Corroborating this, Kisekka et al (1992) posit that ñmaternal mortality ranges between 300 ï 1,000 deaths per 100,000 live births, in Africa compared to 2-9 deaths/100,000 in developed nations. Ò In the northern state of Jigawa in Nigeria, for instance, around 2,000 out of every 100,000 live births result in death for the mother, which is one of the highest rates in the world. About one in every ten women in the state is likely to die of maternity-related causes (DFID, 2007). Each time a woman is pregnant she risks deathé Figures can vary greatly between countries in a region and between areas within a country. The largest number of maternal deaths each year occurs in Asia but the highest risks of pregnancy are in sub-Saharan Africa. Maternal mortality is often much higher in rural than in urban areas with easier access to medical services (Zoe and Sally, 1996). This invariably means that maternal deaths are directly linked to complications resulting from pregnancy or child delivery, in the case of safe motherhood emergency obstetric conditions, poor dieting, non-attendance of antenatal clinic as well as cultural beliefs and behaviours being in the forefront.

In view of this, there is an urgent need to intervene and rescue Nigerian mothers, especially rural women, to ensure that no woman loses her life because of pregnancy by according priority to effective community education about reproductive health, antenatal care, safe delivery, postnatal care, proper and adequate nutrition, as well as mobilizing communities to understand the danger of not promptly seeking quality health care services. It is in this connection that the issue of enhancing consciousness and communicating vital facts to women, as well as men especially in rural communities becomes imperative. Hence, the compelling motivation for creating an informal backdrop on which adequate and relevant information and education can be provided to aid participants (that is, child bearing women, their husbands, and other stakeholders) to make positive choices through reasoning that leads to self-motivated action; and Theatre for Development (TfD) comes handy in this drive towards promoting health and targeting increase in knowledge among the populace regarding health. Drama as a tool for nurturing and educating rural folk can serve as 
a medium to motivate action for self-assertiveness by encouraging behaviour change in an informal context of entertainment and communal get together. In this regard, Osofisan (2004) observes that:

As far as we know, every human society has always been conscious of the need to nurture its youth, promote group solidarity among its members, mobilize its citizens, and from time to time, harness their energies towards some communal project. In order to realize this goal, it invents a number of strategies, among which the theatrical arts are always prominent.

The above statement explicitly explains the didactic nature of drama because drama must entertain but as a channel for entertainment it can be strategically exploited for educative purposes. In other words, what drama does ñis to take the human social incidents and present them as something that needs an explanation and is not to be taken for granted. As such constructive criticism from a social point of view is highly encouragedò (Mbachaga, 2004). Theatre is the art of social relationships because it mirrors the social issues of its time. The issues arising from safe motherhood such as improved family planning utilization, safe delivery, and access to quality and appropriate health care and ante natal care are all social issues within our communities that affect women and drama as an art of ñsocial relationshipsò has the potential of changing behaviour. In essence, drama, particularly its TfD rib, is a potent tool for communicating safe motherhood issues as well as negotiating for change in behaviour and changing perceptions towards safe motherhood issues.

It must be emphasized here that, challenging and changing attitudes as well as beliefs by enhancing sustainable information flow on safe motherhood practices requires confronting the audience with enough reasons and motivation via analyses and discussions so that they are moved to change or improve their behaviour. This article, therefore, presents findings from a study carried out in Ikyaan and Amua communities in Konshisha Local Government Areas of Benue State aimed at promoting maternal 
health consciousness through drama and Participatory Learning and Action (PLA) tools such as focus group discussions, games, interviews, community meetings with local leaders, among others.

\section{Methodology and Process}

Theatre for Development (TfD) based development projects involve the use of drama techniques that involve using people to develop and act out a situation. Thus, this approach is a participatory research approach that utilizes drama and other PLA tools to enhance understanding and raise awareness so as to help people gain a better understanding of the world around them: in this instance; the issue of making pregnancy safer (MPS). The essence is to use drama to trigger discussions or constructive dialogue that eventually leads to action. To this end, the áheatre with the people approachô was used to develop drama skits with the people in the research communities and performed with critical analysis and discussion made with the aid of a facilitator at the end of the episode(s).

Data was generated using drama techniques such as flooding method, and PLA tools such as focus group discussion, in-depth interviews, and semi structured interviews. Discussions of the data were done at a plenary session after the performance of the drama. It is worth noting that; since the data generated was qualitative as such, reports have been presented using the qualitative descriptive method; what is called ñthick descriptionò. The validity of the approach cannot be overemphasized since it affords the target groups the opportunity to fully participate in the process without being passive recipients

\section{Bridging the Gap: Securing Sustainable Development's Promises to the Unreachable}

Amid the ongoing tragedy of maternal mortality and morbidity, reaching the unreachable must be the goal of strategies to improve maternal health care, while securing the promises of sustainable development required that poor women be ñdealt inò to a green economy, the 
Commission on the Status of Women heard today (UN Commission on Women, 2011).

The above quote, opens this segment of this article and places the searchlight on the need for ópening the doorô to womenôs voices and providing the means for their direct participation, in policy development, especially in third world counties such as Nigeria. This is because, women are vulnerable and thousands of women continue to die each year from pregnancy related complications and childbirth due to poverty coupled with illiteracy. What is more, the low statuses of women and inadequate water and sanitation facilities have had a deep impact on health indicators. Beside limited knowledge of illness and wellness, cultural prescriptions, perceptions of a health service and provider and social barriers, cost has been a major barrier to the provision of an effective health service. This has affected the physical and financial accessibility of the health services. Giving voice to women, therefore, ensures womenôs involvement in the issues of health so that they become active participants in the development process in this instance health.

Tegh Tegh (2008), commenting on the involvement of people in development, submits that nit is this lack of involvement of the people in deciding for themselves what the priority areas of development should be that has been a major distraction in the quest for sustainable development.ò The core issue here is that most development programmes in third world counties are barely or totally not inclusive but rather, they are imposed on the people. As such the so called ádevelopersô assume a óknow allô position which breeds strong silence from the people for whom development is meant, thereby excluding them from the centre of determining what happens and or when it happens. However, if development is seen from the perspective of improvement of the lives of people or programmes that enhance the livelihoods of the people, then emphasizing inclusion and or participation of the people becomes imperative.

Julius Nyerere of Tanzania cited in Angya corroborates the foregoing when he posits that just as womenôs development in Africa is dependent on national economic development, so national 
economic development is dependent on the women of Africa and cannot easily take place without them (5). The above means that if meaningful development must be achieved when development programmes are initiated among the rural poor, womenôs needs must be in the fore with emphasis on creating opportunities for women to clearly express themselves without inhibitions.

\section{Community Education for Development: An Overview}

The concept of rural community education encapsulates events that cut across social, economic, educational, judicial, political, health and cultural issues that affect the daily lives of rural folk. Community education is an opportunity for local citizens and community schools, agencies and institutions to become active partners in addressing education and community concerns. It is a form of education that brings community members together to identify and link community needs and resources in a manner that helps people to raise the quality of life in their communities.

Community education (CE) is a unique education concept that embraces certain beliefs: education is a lifelong process; as such everyone in the community - individuals, religious bodies, public and private agencies - shares responsibility for the mission of educating all members of the community; and citizens have a right and a responsibility to be involved in determining community needs, identifying community resources, and linking those needs and resources to improve their community. CE results in: efficient and cost-effective ways of delivering education and community services; broad-based community support for schools and other community agencies; an emphasis on special populations, such as at-risk youth and minorities; and collective action among all educational and community agencies to address quality of life issues. Lowe cited in Moemeka (1981) while discussing rural community education posits that ñll attempt to change attitude and behaviour involve the educative process, since, in order to change, people must first acquire fresh knowledge, insights and skills.ò In this sense, Moemeka sees education as the prime key to motivating 
people to action in what he described as ña nourishing blood streamò that courses through all aspects of rural community development (1981).

Furthermore, Paolo Freire, the Brazilian adult educator believes that education can only be true and free if the learners are treated as active participants and subjects rather than objects of the learning process. To this end, Freire advocated for an alternative approach to education which he called problem posing approach because he felt that the situation where a teacher gives information to students by lectures in a formal setting $\ddot{i}$ the banking approach, treats people as objects or empty vessels and passive recipients of chosen information was not good enough (1970). The essential issue here is that this education is not necessarily formal $\ddot{i}$ the type that solely ends in obtaining a certificate but it is concerned with strategically raising the consciousness of the people with the aim of improving their lives and lot. Moemeka further submits that, ñthis is an education which brings the learner to a situation where he can examine critical actions which he had previously accepted as given, begins to see that reality is not a closed world from which there can be no exit; and perceives his own situation as one that he himself can alterò(1981).

This means that changing attitudes and behaviour involves changing perceptions and existing beliefs that had been previously accepted as the norm. One can, therefore, boldly submit that preparing groups or communities towards achieving meaningful goals within the context of development requires the impartation of basic skills that are required for and relevant to the social, economic and political development of the individual in particular and society in general. Any meaningful development programme should be the type that places high priority on the education of the people so as to prepare the people to understand what is taking place around them and stimulate them to participate in shaping the change that has been triggered. If development can be seen as a fabric woven out of the activities of millions of people, then TfD as a paradigm aimed at arousing the consciousness of the people represents the essential thread that binds them together. A development strategy that uses communication approaches that 
reveal peopleôs underlying attitudes and traditional wisdom helps people to adapt their views and to acquire new knowledge and skills, and spread new social messages to large audiences. The planned use of communication techniques and activities gives people powerful tools both to experience change and actually to guide it. An intensified exchange of ideas among all sectors of society can lead to the greater involvement of people in a common cause.

Developing dialogue between the teachers and learners becomes imperative to this approach so that the learners in the long run, build the ability to make decisions and solve problems. This approach is encapsulated in Friereôs theory of ñconscientizationò (1970), which aims at developing a deeper understanding of situations in a bid to be able to take action to change such situations. This is because, if people increase their critical awareness of the reasons why situations or certain conditions are the way they are, they will then understand these situations or conditions better and in turn take required steps to change or improve the situation. In the same vein, Augusto Boalôs theory emphasizes the use of drama as a language for all which should be harnessed towards enhancing change (Rifkin and Pridimore, 2001). Here, drama is seen as a participatory approach through which targeted communities are involved in the whole process of generating messages and exploring issues that affect their lives.

\section{Findings and Discussions}

It was eminent during the discussions at Ikyaan that there is poor knowledge of maternal danger signs and their causes. This is because most women could only name swollen legs which in the local dialect is called Angahar a mullan and bleeding, Yav mbu haan, and abdominal pain. Although, at Amua knowledge of danger signs was higher compared to Ikyaan because women and men readily mentioned signs of impending danger such as:

- Severe vomiting

- High fever

- Bleeding from the vagina

- Yellowing of the eyes 
- Weakness of the body and tiredness

To further enhance the knowledge base community discussion groups were established; whose discussion topics focused on the danger signs of pregnancy and emphasis was placed on making the discussants know what to do when an obstetric emergency occurs, where to seek help, and planning for safe pregnancy. These discussions were facilitated by local health providers that are respected and whose opinions are held in high esteem and fully supported by local leaders such as the local priest and the traditional head(s). Another issue that was captured and exhaustively discussed was the issue of home based delivery which was preferred by women. Further probing during the group discussions as well as discussions at plenary revealed that most women do not prepare financially for the pregnancy as such the inability to settle hospital charges makes them stay at home and prefer home based delivery which is less expensive and often handled by traditional birth attendants (TBAs). As one woman put it:

Ka se hemba soon u maren ke ya sha a ciu $m$ mban u nyar shi njaa I you ichi ka i luga man ke ya yo ka we lu a nyaregh ga kpa u mar sha ikyev I kwase mar ke iyou ichi yo ka I venda $u$ koron we mar shie u fe tyo u kimbin njaa ga yo.

\section{Translation}

We prefer home based delivery because often we do not have money to foot the hospital bills and the TBA still assists. But in hospital if you do not pay the fee they won't attend to you" (woman aged 26 with 2 children at Ikyaan).

The above preference is linked to the fact that traditional healers, diviners as well as TBAs are easily accessible, and cheaper compared to the other local health providers. It suffices that payment for treatment provided by herbalists can be made in form of chickens, small amount of money, and sometimes free treatment. 


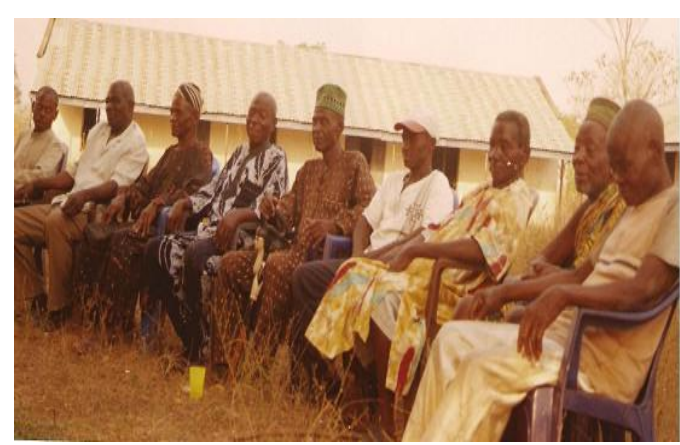

Plate 1: Cross section of elders at Ikyaan during workshop

An interesting event to buttress the importance of clinic based delivery occurred on day one at Amua. As the drama activists arrived and were moving to the residence of the traditional head; a lady who was pregnant and in labour literally delivered her child in a wheel barrow. Enquiries revealed that it was her third pregnancy and she has not attended antenatal clinic because she normally delivers at home without complications and when the labour pangs began, she had no one to help her. This was used as an illustration by the activists to further drive home the message of clinic based delivery and planning for pregnancy. During discussion of the need for planning pregnancy at plenary, a man at Ikyaan community had this to say:

Maa mbu kwase u ya mbu inja er ka ura noon nahan. Or fe shie u mbu soo u noon ga nahan doo u wan agoiyol shie u kwase nan lu iyav man mbu ngboom ikua a mar yôò.

\section{Translation}

A woman's pregnancy and delivery can be likened to rain which does not tell anyone when it wants to pour down as such, it is needful and proper to prepare for the unknown surprises that pregnancy can bring when a woman is pregnant" (Aer Gabriel 47 years). 
This triggered serious accusations and counter accusations regarding the issue of financial support from the men and lead to deep discussions on the role of men during and after delivery as well as womenôs autonomy among participants in the research communities. It is imperative to mention here that in the Tiv traditional setting, men play a vital role in determining the health needs of a woman. Since men are decision makers and in control of all the resources, they decide when and where women should seek health care. Women are usually not allowed to visit a health facility or health care provider without first seeking the permission of their husbands or to make the decision to spend money on health care. Thus women generally cannot access health care in emergency situations.

Again, women are socially dependent on men and lack of economic control reinforces their dependency. Discussions in this instance helped participants because the men at plenary agreed that women should be allowed some autonomy to own certain domestic animals such as chickens and goats to be able to sell same and prepare for emergencies and or pay for bills. As well, discussions centred on men allowing their wives to make the decision of seeking medical care in a hospital without waiting for them especially in pregnancy related situations.

It is pertinent to note that the issue of ónome based deliveriesôwas recurrent in the discussions with health providers and community groups as a result of these findings. The discussions focused on what the men and women in the research communities need to do, to ensure healthy and safe pregnancies with emphasis on receiving care from qualified nurses and having regular monthly checkups as soon as a woman discovers that she is pregnant. 


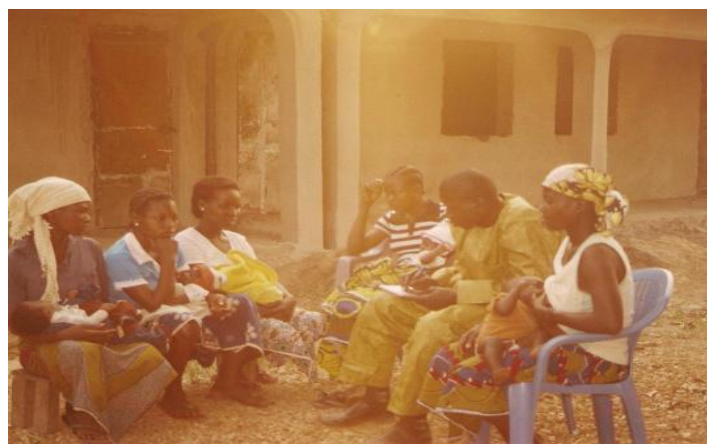

Plate 2: FGD with women who delivered babies in clinics during follow up

The above re-echoes the strength of the TfD process in giving inspiration to communal life by providing the means through which issues affecting the peopleôs lives are explored and addressed. It offers a means of reflecting why and how changes might be necessary and can come about. This is why TfD practitioners seek to create or do theatre with the peopleôso as to encourage collective decisions from the people that can change their realities. In both communities, there was low knowledge regarding the issue of mother to child transmission (MTCT) prior to the drama performance. The communities had not heard of it before this time. The activist aided by the local health providers enlightened the people on the risks and suggested where to get help. This led to the discussion of HIV/AIDS on a large scale. Discussions bordered on safer sex practice, as well as how to avoid risky behaviour, including discussions on the use of condoms as well as other contraceptives with a practical demonstration on how to use a condom.

Table 1 showing local names of HIV/AIDS gleaned in the research communities

\begin{tabular}{|lc|l|l|}
\hline $\begin{array}{l}\text { local names for } \\
\text { HIV/AIDS }\end{array}$ & $\begin{array}{l}\text { Lace, Agbeda, Anakande, Danzaria, } \\
\text { Horityo, }\end{array}$ \\
\hline
\end{tabular}

Source: Interviews in Research Communities, 2007. 
At Ikyaan, the story was not different either because women and men prior to the drama workshop did not know about the mother to child transmission of the HIV/AIDS virus. On the whole, discussions during plenary enabled several participantsô access to new knowledge as one woman put it:

Mayange je $m$ fa me anakande u ken kwase u ya $u$ ne faityo u peren ken wan shie u nan lu ken $u$ ya la ga kpa inumbe ne tam iwanger waan".

\section{Translation}

I never knew that an unborn child could contact HIV from its mother until now through this drama (Mrs Myanyi Saawuan 32 year old woman)

Here, Jack Mezirowôs concept of transformative learning is strongly applies because most participants in the workshops, by reflecting on the issues presented in the skits, changed their previous frames of mind and beliefs regarding certain experiences by making new meaning of their cultural and contextual experiences (2012). The drama skits in this instance triggered open reflections on health issues pertaining safe motherhood and through the personal involvement in the analysis of the drama episodes which help to influence a shift in the participants.

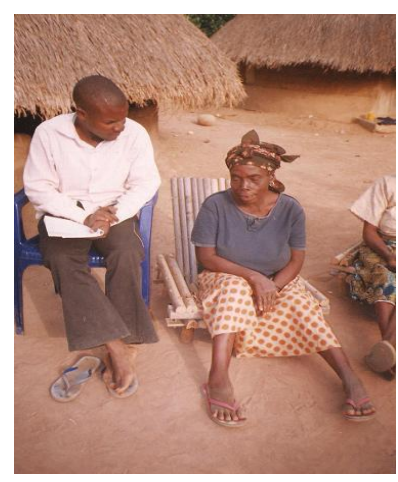

Plate 3: Interview with a TBA 
The core issue here is about using drama to make personal understanding of issues or beliefs, through assessing the evidence and arguments of a point of view, and being open to looking at alternative points of view, or alternative beliefs, then reflecting critically on the new information, and making a personal judgment based on a new assessment of the information. The transformative power of the theatre is in its ability to challenge individuals, communities, and groups to expand the existing mindsets so as to be able to enhance their traditional world views. In this regard, HIV/AIDS discussions at Amua revealed that most people prior to the drama performance knew about the disease but they believed that if one is taking the anti-retroviral drugs (ART) he or she does not need to use a condom. Hence, the drug controls the virus. This again connects to the health belief theory earlier mentioned. As one man put it this way:

A lu or ngu menan ichigh ki anakande yo nan a kera wa jubu ga kpa ka kwagh ga sha ciu cigh kira ka ki yange anakande la u perer ken or gen.

\section{Translation}

If someone who is positive is taking antiretroviral drugs, the person may not need condoms again when having sex since the drugs he is taking will prevent his partner from getting the disease from him (Mchihi Amu, man with 3 wives, 39 yrs Amua village).

This kind of misconception was corrected by explaining what antiretroviral drugs do and further discussions on the need for safe sex by using condoms even if you are still taking the ART drugs to avoid contracting another type of HIV or transmitting it to your partner. This confirms the place of belief in influencing health behaviour as presented in the health belief model. 


\section{Summary of Findings}

1. Poverty is a strong reason why the people prefer ónome based deliveryôto ớacility based deliveriesôbecause home based deliveries are cheaper compared to the charges incurred at the health centres. This means poverty is a strong barrier hindering access to timely and quality care by pregnant mothers in the communities. This is corroborated by Kofi Annan (2001) when he said ñthe biggest enemy of health in the developing world is poverty.ò

2. Knowledge as regards the mother to child transmission of HIV/AIDS was low prior to the drama intervention.

3. Prior to the drama presentation most women as well as men felt that if one is taking the anti-retroviral drugs he or she does not need to wear a condom, a misconception that was corrected. More so, prior to the drama presentation, some people had not heard of the anti-retroviral and its function and where to access treatment and management.

\section{Conclusion/ Recommendations}

Access to good health is one of the most serious challenges faced by women in third world countries. This is why Mbachaga (2010) citing NEPAD submits that ñthe health challenge of people in rural areas across in Nigeria and indeed in Africa is a threat and burden and one of the most serious casualties consequent on the poverty, social exclusion, marginalization and lack of sustainable development. This article has discussed the issue of womenôs health and emphasized that meaningful development is the type that places high priority on the education of the people so as to prepare them to understand what is taking place around them and stimulate them to participate in shaping the change that has been triggered.

Concerted effort should be put into the alleviation of poverty in rural communities in Nigeria as evidence from Ikyaan and Amua show that poverty and ill health are part of a vicious circle in which poverty undermines health, and ill health contributes to poverty, which explains why individuals and sometimes whole communities are unable to escape from the poverty trap. There is also the need to create avenues for public communication regarding health literacy so as to effectively 
empower people to take action to improve their health. This can be done through collaborative efforts of the local government health departments, local health providers as well as community members. Moreover, drama and drama related programmes have been used successively to promote this issue and should continuously be utilized in this regard to persuade, inculcate, and to educate or reorient rural folk.

\section{References}

Angya C.A. Development projects and effects on women and children in Benue State, Nigeria: An Assessment of DFID assisted Benue Health Fund Project (BHF). Np.

Annan, K. (2001). Poverty, biggest enemy of health in developing world. Retrieved 13 Nov. 2010, from www.un.org/sgsm7808.doc.htm.

DFID. (2007). Case studies: Saving mothersô lives in northern Nigeria. Retrieved 10 Nov. 2010, from http//:www.dfid.gov.uk/casestudies/files/Africa.

Eric, B. (2003). The new partnership for Africa's development (NEPAD) health strategy. Abuja: NEPAD Nigeria.

Federal Ministry of Health. (2005). Health promotion policy for Nigeria. Retrieved 7 Oct. 2010, from http://www.fmh.gov.ng/pdfs/drafts.

Freire, P. (1970). Pedagogy of the oppressed (Translated by Myra Bergman Ramos). New York: Seabury Press.

Kisekka, M. N. et al. (1992). Women's health issues in Nigeria. Zaria: Tamaza Pub. Company Ltd.

Marie Stopes International. (2004). Safe motherhood: Essential health care and human rights Retrieved 19 Oct 2007, from Http//www.mariestopes.org.uk/ww/safemotherhood.htm.

Mbachaga, J. D. (2010). Theatre for development, participatory monitoring and feedback: The Example of Ikyaan and Amua Communities in Benue State. An unpublished paper. . (2004). Fostering safer sex among secondary school teenagers through drama: A study of selected secondary 
schools in Makurdi township area. Unpublished M.A. dissertation, Department of Theatre Arts, Benue State University, Makurdi.

Mezirow, J. (2012). Transformative learning. Retrieved 20 March 2017, from theory.com/index.html.

Moemeka, A.M. (1981). Local radio: Community education for development. Zaria: Ahmadu Bello University.

National Population Commission, Nigeria. (2013). Nigeria demographic and health survey: Preliminary report. Abuja: National Population Commission of Nigeria. Retrieved 19 Sept 2014, from http://dhsprogram.com/pubs/pdf/PR41/PR41.pdf.

Osofisan, F. (2004). Communicating children and women's rights in Nigeria: Experiences from the field. Abuja: UNICEF.

Rifkin, S.B. and Pridimore, P. (2001).Partners in Planning. London: Macmillan.

Tegh Tegh, D. (2008). Developing community strategy for sustainable development: The Shange la-Mwem model. In Izuu Nwankwo et al (Eds). Book of proceedings for Professor Femi Osofisan international conference on performance. Awka. Valid Publishing.

United Nation Population Fund (UNFPA). (2006). Fact sheet. New York: UNFPA.

United Nations Commission on the Status of Women. Reaching the unreachable, securing sustainable developmentôs promises can reverse maternal mortality trends, integrate women in green economy, commission told. Retrieved 12 Sept 2014, from http://www.un.org/News/Press/docs/2011/wom1847.doc.ht $\mathrm{m}$.

Zoe, O. and Sally, B. (1996). Challenges to women's reproductive health: Maternal mortality. Bridge to development ï gender report no. 38. Brighton: Institute of Development Studies University of Sussex Brighton. Retrieved 9 Oct 2007, from http:// www.ids.ac.uk/bridge. 